\title{
Cave swiftlet: a new horizon in Malaysia's tourism industry
}

\begin{abstract}
The aim of this paper is to explore the potential of activities as well as the visual effects surrounding the up-keeping and harvesting of swiftlet nests in caves as a new tourism product for Malaysia. As an industry, tourism needs a continuous stream of products, established and emerging ones, to accommodate not only the increasing numbers of tourist arrivals but also increasing demand for new forms of tourism products. Tourists are also increasingly getting sophisticated in their taste of tourism products, including their desire to participate in sustainable forms of tourism which means that the activities they indulge during their visits have little impacts on the environment. This paper is a manifestation of an earlier part of a research exercise to identify and visit caves inhabited by swiftlets. Gomantong, Sabah, set the research journey. Observation and in-depth interviews formed the study's tool. Rich data collected are also integrated with secondary data. Findings show that harvesting activities on cave ceilings produce a spectacular scene to viewers, inducing a magnet of attraction to tourists. On the other hand, a decline in the amount of nests harvested in the last few years may raise the idea that such activities in its prevalence may not dwell well with the issue of sustainability.
\end{abstract}

Keyword: Bird Nest; Cave; Gomantong; Swiftlet; Tourism 